\title{
Review on Role of Proline on Coffee Under Drought Conditions
}

\author{
Wubishet Tamirat \\ Ethiopian Institute of Agricultural Research, Jimma Agricultural Research Center \\ P.O. Box 192, Jimma, Ethiopia
}

\begin{abstract}
Drought is one of the major constraints that limiting production of crop worldwide. Plants tolerate drought by many ways like morphological, physiological and biochemical tolerance mechanisms. Plants develop mechanisms to tolerant abiotic stress by osmotic adjustment that is usually accomplished by uptake of inorganic ions, as well as the accumulation of proline. Proline is a universal osmo-protectant and acts as an osmolyte and antioxidant, and it is one of the most important compatible solutes that play a vital role in osmotic adjustment in crops under drought stress. Accumulation of proline considered as adaptive mechanisms in drought-tolerant coffee genotypes. In general, more attention on biochemical traits for drought tolerant mechanisms on coffee should be given. Therefore, looking for high proline accumulation genotype under drought conditions is important for further coffee breeding program to release drought tolerant genotypes.
\end{abstract}

Keywords: Coffee, Drought, Tolerant, Proline Accumulation

DOI: $10.7176 / \mathrm{JEES} / 9-10-01$

Publication date:October $31^{\text {st }} 2019$

\section{Introduction}

Plant growth and productivity are affected by different environmental factors like water deficit, temperature extremes, salinity, toxic metal ion concentration and UV radiation. Plants accumulate large quantities of different types of compatible solutes depending on different stress. Compatible solutes provide protection to plants from stress by contributing to cellular osmotic adjustment, reactive oxygen species detoxification, protection of membrane integrity and enzymes or protein stabilization (Ashraf and Foolad, 2007; Shamsul et al., 2012), these compatible solutes are proline, sucrose, polyols, trehalose and quaternary ammonium compounds such as glycine betaine, alinine betaine, proline betaine and pipecolate betaine (Serraj and Sinclair, 2002).

Proline is a proteinogenic amino acid with an exceptional conformational rigidity, and is essential for primary metabolism (Szabados and Savoure, 2010). Proline accumulation has been reported under drought, high salinity, high light and UV irradiation, heavy metals and oxidative stress conditions (Yoshiba, 1995; Fabro et al., 2004; Choudhary et al., 2005; Haudecoeur et al., 2009). Drought stress imposed by withholding irrigation induced proline accumulation in coffee leaves. The difference was observed on both Arabica and Robusta coffee cultivars for the concentration of leaf proline under both control and drought-stressed conditions, but stressed plants accumulated substantially higher level than control (Maestri et al., 1995). Similarly, several workers have correlated drought tolerance with increase in leaf proline concentration during genotype screening for drought tolerance (Heuer, 1999; Hassan et al., 2003). Increase in proline accumulation in leaves of drought-stressed coffee plants was associated with decrease in leaf water potential, and thus a mechanism of osmotic adjustment in cells or maintenance of turgidity to overcome the stress (Tesfaye et al., 2014).

Proline is believed to be one of the most important compatible solutes that play a vital role in osmotic adjustment in crops subjected to water deficit stress. In generally, accumulation of proline has been regarded as a tolerance mechanism and adaptation of genotypes to drought stress. Therefore, the objective of this paper is to review the role of proline on coffee under drought conditions.

\section{Proline synthesize}

In plants, proline is synthesized by two pathways viz. glutamate and orinithine pathway (Figure 1) (Szabados and Savoure, 2010; Shamsul et al., 2012). Glutamate pathway is account major proline accumulation during osmotic stress. Proline is synthesized from this pathway, which is reduced to glutamate semi-aldehyde (GSA) by the pyrroline-5-carboxylate synthetase (P5CS) enzyme and converted to pyrroline-5-carboxylate (P5C). The P5C reductase (P5CR) further reduces the P5C intermediate to proline (Szoke et al., 1992; Verbruggen et al., 1993). Orinithine pathway, which is transaminated first by ornithine-delta-amino transferase (OAT) producing GSA and P5C, which is converted to proline (Verbruggen and Hermans, 2008). 


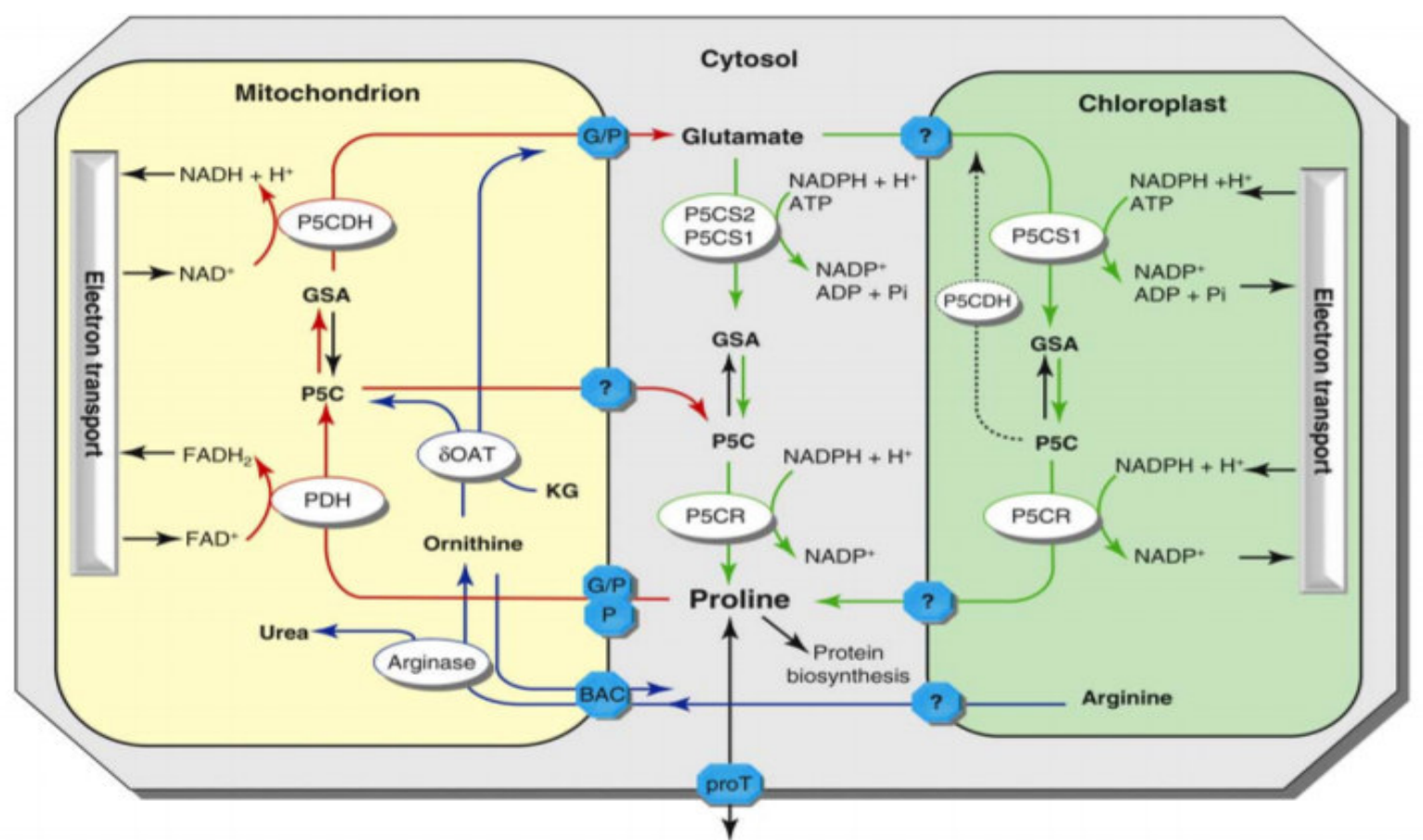

Figure 1. Proline metabolism in higher plants. Abbreviations: BAC: basic amino acid transporter involved in arginine and ornithine exchange; Glu: glutamate; G/P: mitochondrial glutamate/proline antiporter; $K G$ : alpha-ketoglutarate; P: mitochondrial proline transporter; Pi: inorganic phosphate; ProT: plasma membrane proline transporter. The biosynthetic pathway is marked with green lines, the catabolic pathway with red lines and the ornithine pathway with blue lines. Source: Szabados and Savoure (2010).

\section{Function of Proline}

Proline is considered as an inert compatible osmolyte that protects sub-cellular structures and macromolecules under osmotic stress (Kishor et al., 2005). Proline accumulation can influence stress tolerance in multiple ways (Figure 2). Proline has been shown to function as a molecular chaperone able to protect protein integrity, enhance the activities of different enzymes, prevent of protein aggregation and stabilization of lactate dehydrogenase during extreme temperatures, protection of nitrate reductase during heavy metal and osmotic stress, stabilization of ribonucleases and proteases upon arsenate exposure (Mishra and Dubey, 2006). It is important for protein synthesis, has protective functions as an osmolyte, contributes to the maintenance of the redox balance, can regulate development and is a component of metabolic signaling networks controlling mitochondrial functions, stress relief and development (Szabados and Savoure, 2010).

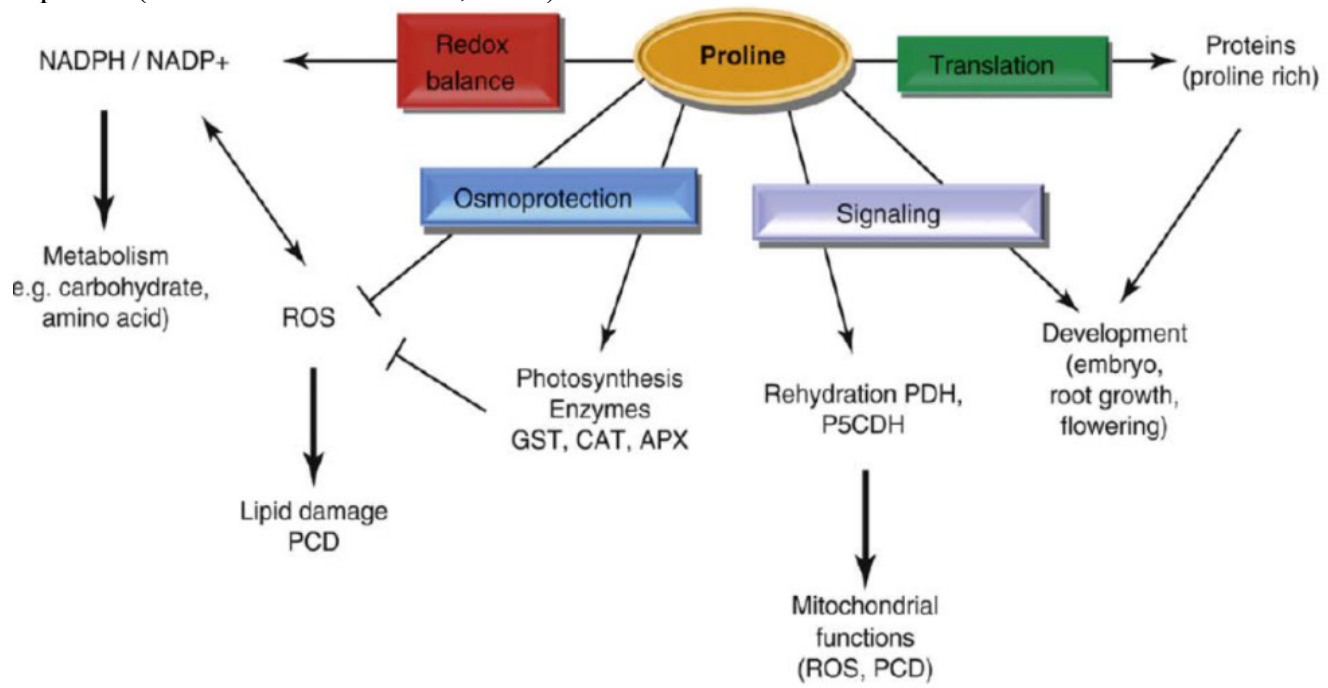

Figure 2. Function of proline. Abbreviations: APX: ascorbate peroxidase; CAT: catalase; GST: Glutathione Stransferases; PCD: programmed cell death; P5CDH: P5C dehydrogenase; PDH: proline dehydrogenase; ROS: reactive oxygen species. Source: Szabados and Savoure (2010). 


\section{Proline Accumulation on Coffee under Drought Conditions}

Plants vary in their capacity to tolerate drought depending on genetic constitution. High osmotic adjustments occur in the drought tolerant cultivars through accumulation of solute such as free proline which increase the bound water capacity, regulate stomatal movement, trigger water uptake, induce heat stability and maintain the integrity of the cell membrane (Venkataramanan, 1985), because of its role in osmotic adjustment (OA), accumulation of proline in plant tissue under water deficit condition has been also considered as one of the adaptive mechanisms in drought-tolerant genotypes (Heuer, 1999). Proline accumulation on leaves of four Arabica coffee cultivars were done, from these Dawairi and Tessawi are better stresses tolerant due to highest levels of proline in their leaves as compared to other cultivars (Figure 3) (Tounekti et al., 2018). Similarly, favorable changes in biochemical composition like higher accumulation of epicuticular wax, free proline, total protein content and chlorophyll fractions in drought tolerant genotypes has been reported in coffee (D' Souza et al., 2009).

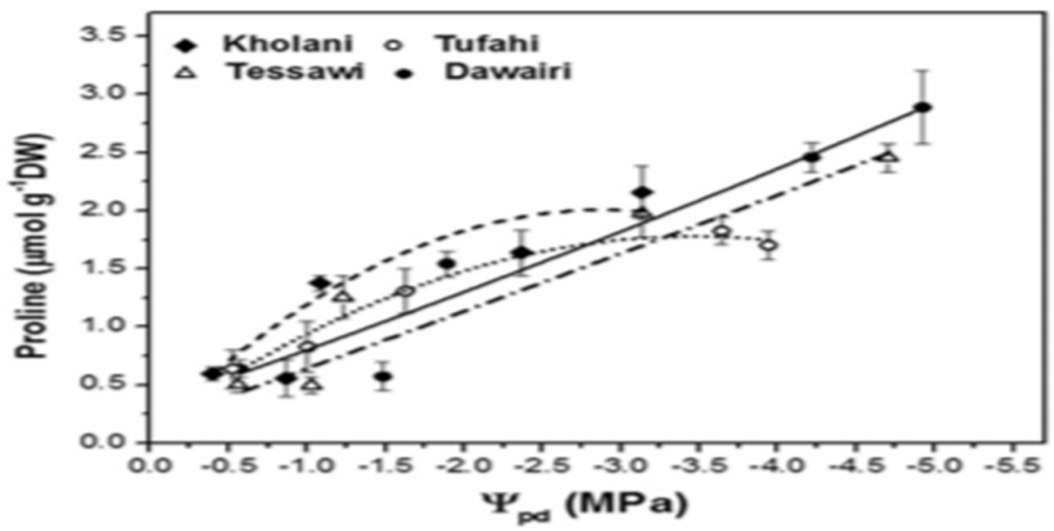

Figure 3. Proline contents as a function of predawn leaf water potential ( $\Psi p d)$ in Arabica coffee cultivars (Kholani, Tessawi, Tufahi and Dawairi) subjected to drought. Bars indicate standard errors of the means. Source: Tounekti et al. (2018).

Robusta coffee clones (IC-2, IC-3, IC-4, IC-6, IC-8 and R-4) were subjected to two treatments: well-watered control and drought-stressed, the results revealed that leaf proline concentration substantially increased with time of exposure of the plants to soil drying. Clones IC-6 and IC-3 are drought tolerant than other clones due to higher proline accumulation (Table 1), the drought tolerant mechanisms could be linked to osmotic adjustment due to more accumulation of proline. In Figure 5 leaf proline concentration of all the clones decreased when the plants were re-watered (Tesfaye et al., 2014).

Table 1. Leaf water potential (LWP), leaf proline concentration (LPC) as estimated by visual stress score values (SSV) and proportion of plants showing complete wilting symptoms (PPCWS) on day 12 of soil drying.

\begin{tabular}{ccccc}
\hline Clone & $\begin{array}{c}\text { LWP } \\
(\mathrm{MPa})\end{array}$ & $\begin{array}{c}\text { LPC }(\mu \text { molg- } \\
\text { Fresh weight })\end{array}$ & $\begin{array}{c}\text { SSV } \\
(1-5 \text { scale })\end{array}$ & $\begin{array}{c}\text { PPCWS } \\
(\%)\end{array}$ \\
\hline IC-2 & -3.2 & 10.0 & 3.10 & 96.80 \\
IC-3 & -3.2 & 12.2 & 2.50 & 86.80 \\
IC-4 & -3.4 & 9.4 & 3.33 & 96.80 \\
IC-6 & -3.3 & 13.3 & 2.33 & 86.80 \\
IC-8 & -3.3 & 9.0 & 3.33 & 96.80 \\
R-4 & -3.3 & 9.5 & 3.40 & 96.80 \\
\hline
\end{tabular}

Source: Tesfaye et al. (2014).

Proline levels increased significantly in roots and leaves of stressed coffee cultivars (Figures $4 \mathrm{a}$ and $\mathrm{b}$ ). Proline contents measured in leaves and roots of stressed and unstressed coffee cultivars were used as a biochemical marker of drought stress (Santos and Mazzafera, 2012). On the other hand, Silva et al. (2010) reported that proline accumulation was higher in leaves of a drought tolerant clone of Coffee canephora than in the susceptible. 


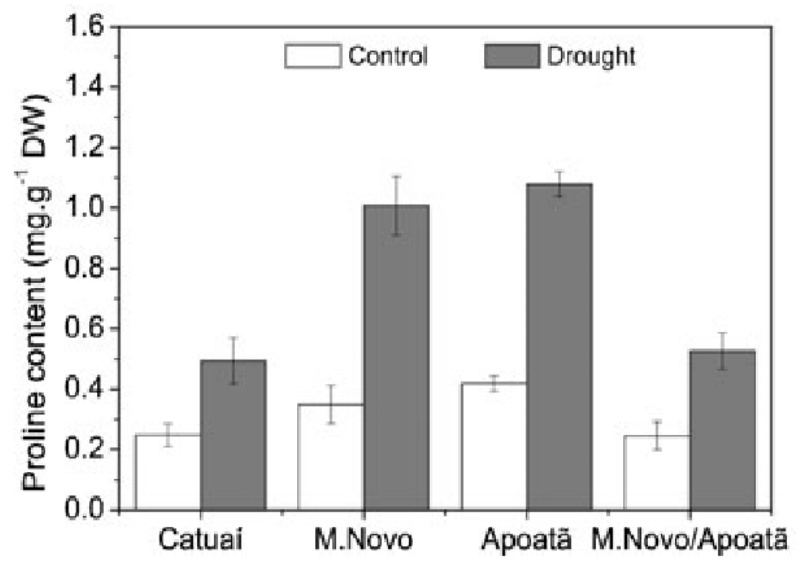

(a)

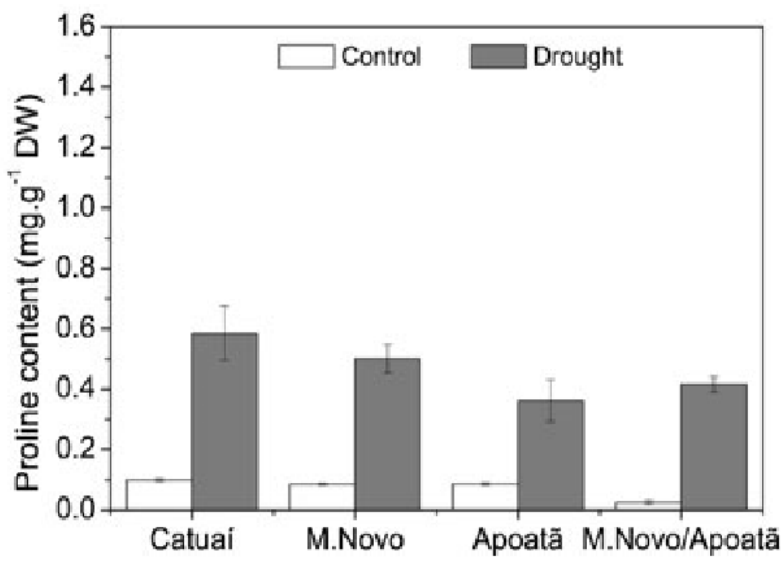

(b)

Figure 4. Proline contents in leaves (a) and roots (b) of stressed and control coffee plants. Bars indicate standard errors of the means. Source: Santos and Mazzafera (2012).

At water stress conditions Sln.10 scion on Sln.11 rootstock and S.795 and S.4202 scions on Sln.9 rootstock maintained significantly higher free proline. The soil moisture regimes indicated significantly higher proline content in the graft combinations indicating drought adaptability mechanisms (Somashekhargouda et al., 2019). Similar observations were earlier documented in coffee (Renukaswamy et al., 2008). As shown in Table 2, compared to conventional drip irrigation, alternate drip irrigation increased the content of proline by $69.6 \%$ and fixed drip irrigation by $204.6 \%$ (Liu et al., 2016).

Table 2. Effect of drip irrigation method and super absorbent polymer on coffee physiological parameters.

\begin{tabular}{cccc}
\hline $\begin{array}{c}\text { Drip Irrigation } \\
\text { Method }\end{array}$ & $\begin{array}{c}\text { Super Absorbent } \\
\text { Polymers Level }\end{array}$ & $\begin{array}{c}\text { Leaf Water } \\
\text { Content }(\%)\end{array}$ & $\begin{array}{c}\text { Proline } \\
\left(\mathrm{ig} \mathrm{g}^{-1}\right)\end{array}$ \\
\hline \multirow{2}{*}{ ADI } & SAP & $75.72 \pm 1.14 \mathrm{a}$ & $9.46 \pm 1.58 \mathrm{~b}$ \\
& NSAP & $71.38 \pm 0.91 \mathrm{ab}$ & $18.30 \pm 2.82 \mathrm{~b}$ \\
FDI & SAP & $72.86 \pm 1.27 \mathrm{ab}$ & $17.33 \pm 0.95 \mathrm{~b}$ \\
& NSAP & $67.68 \pm 0.84 \mathrm{~b}$ & $32.53 \pm 2.53 \mathrm{a}$ \\
CDI & SAP & $75.75 \pm 3.35 \mathrm{a}$ & $6.17 \pm 0.91 \mathrm{~b}$ \\
& NSAP & $75.95 \pm 2.40 \mathrm{a}$ & $10.20 \pm 0.90 \mathrm{~b}$ \\
\hline
\end{tabular}

Abbreviations: ADI, FDI and CDI: represent alternate drip irrigation, fixed drip irrigation and conventional drip irrigation. SAP and NSAP: represent added superabsorbent polymers and no superabsorbent polymers, respectively. The values are means \pm standard errors $(n=4)$. Different letters in the same column indicate significant difference $(P<0.05)$. Source: Liu et al. (2016). 

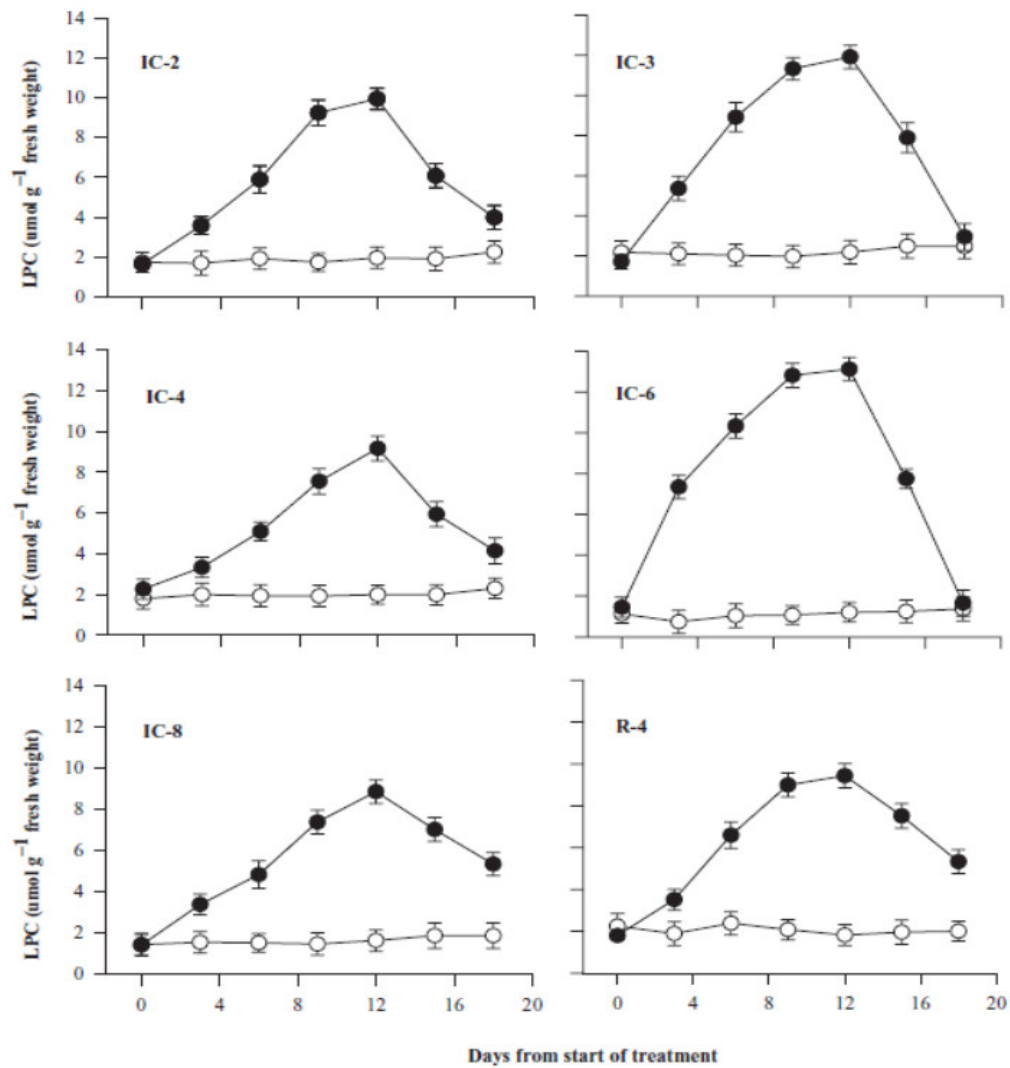

Figure 5. Leaf proline concentration (LPC) of six Robusta coffee clones as affected by soil drying and re-watering on day 12 when complete wilting symptoms were observed (open symbols represent well-watered and closed ones water-stressed treatments). Bars represent standard error of means of each three observations. Source: Tesfaye et al. (2014).

\section{Conclusion}

Ethiopia is center of origin and diversity of Arabica coffee. Coffee crops tolerate drought by different mechanisms like morphologically, physiologically and biochemically. Proline accumulation in plant tissues under water deficit condition is considered as adaptive mechanisms in drought-tolerant genotypes, because of important role in osmotic adjustment. In general, plants with high proline accumulation are known to be drought tolerant. Therefore, to overcome future drought problems on Arabica coffee, strong research should be needed on biochemical as well as morphological and physiological drought tolerant mechanisms.

\section{References}

Ashraf, M.F.M.R. and Foolad, M. 2007. Roles of glycine betaine and proline in improving plant abiotic stress resistance. Environmental and experimental botany, 59(2): 206-216.

Choudhary, N.L., Sairam, R.K. and Tyagi, A. 2005. Expression of delta-pyrroline-5-carboxylate synthetase gene during drought in rice (Oryza sativa L.). Indian Journal of Biochemistry and Biophysics, 42: 366-370.

D'Souza, G. F., Renukaswamy, N. S., Anand, C. G., Awati, M. G. and Lamani, B. 2009. Biochemical and physiological changes in two arabica coffee genotypes in relation to drought tolerance. Journal of Coffee Research, 37(1\&2): 26-42.

Fabro, G., Kovacs, I., Pavet, V., Szabados, L. and Alvarez, M.E. 2004. Proline accumulation and AtP5CS2 gene activation are induced by plant-pathogen incompatible interactions in Arabidopsis. Molecular Plant-Microbe Interactions, 17(4): 343-350.

Hassan, I. A., Mohd Razi, I., Mohd Mokhtaruddin, M. and Halimi, M. S. 2003. Effect of partial root zone drying (PRD) on growth, yield and water use efficiency (WUE) of tomatoes on soil less culture. Transactions of Malaysian Society of Plant Physiology, 12: 128-139.

Haudecoeur, E., Planamente, S., Cirou, A., Tannieres, M., Shelp, B.J., Morera, S. and Faure, D. 2009. Proline antagonizes GABA-induced quenching of quorum-sensing in Agro-bacterium tumefaciens. Proceedings of the National Academy of Sciences, 106(34): 14587-14592.

Heuer, B. 1999. Osmoregulatory role of proline in plants exposed to environmental stresses. In Hand book of Plant and Crop Stress, 675-695. 
Kishor, P.K., Sangam, S., Amrutha, R.N., Laxmi, P.S., Naidu, K.R., Rao, K.R.S.S., Rao, S., Reddy, K.J., Theriappan, P. and Sreenivasulu, N. 2005. Regulation of proline biosynthesis, degradation, uptake and transport in higher plants: its implications in plant growth and abiotic stress tolerance. Current Science, 88(3): 424-438.

Liu, X., Li, F., Yang, Q. and Wang, X. 2016. Effects of alternate drip irrigation and superabsorbent polymers on growth and water use of young coffee tree. Journal of environmental biology, 37(4): 485.

Maestri, M., Da Matta, F. M., Regazzi, A. J. and Barros, R. S. 1995. Accumulation of proline and quaternary ammonium compounds in mature leaves of water stressed coffee plants (Coffea Arabica and C. canephora). Journal of Horticultural Science, 70: 229-233.

Mishra, S. and Dubey, R.S. 2006. Inhibition of ribonuclease and protease activities in arsenic exposed rice seedlings: role of proline as enzyme protectant. Journal of Plant Physiology, 163(9): 927-936.

Renukaswamy, N. S., D’Souza, G. F., Divya, K. S., Awati, M. G., Lamani, B., Anand, C. G., Venkataramanan, D. and Jayarama. 2008. Biochemical and physiological aspects of moisture stress in Coffea arabica L. In Golden jubilee conference on "Challenges and Emerging Strategies for improving plant Productivity". November 12-14, 2008, IARI, New Delhi, India. Abstract 76.

Santos, A.B. and Mazzafera, P. 2012. Dehydrins are highly expressed in water-stressed plants of two coffee species. Tropical plant biology, 5(3): 218-232.

Serraj, R. and Sinclair, T.R. 2002. Osmolyte accumulation: can it really help increase crop yield under drought conditions?. Plant, cell \& environment, 25(2): 333-341.

Shamsul, H., Qaiser, H., Alyemeni, M.N., Wani, A.S., Pichtel, J. and Aqil, A. 2012. Role of proline under changing environments: a review. Plant Signaling and Behavior, 7(11): 1456-1466.

Silva, E.A. and Mazzafera, P. 2008. Influence of temperature and water on coffee culture. The Americas, 2(2): 3241.

Somashekhargouda, P., D’Souza, G.F., Umesh, D.K. and Rudragouda, C. 2019. Rootstock scion interaction effects on biochemical and gas exchange drought tolerant traits in Arabica (Coffea arabica L.) coffee. Plant Physiology Reports, pp.1-12.

Szabados, L. and Savoure, A. 2010. Proline: a multifunctional amino acid. Trends in plant science, 15(2): 89-97.

Szoke, A., Miao, G.H., Hong, Z. and Verma, D.P.S. 1992. Subcellular location of delta 1-pyrroline-5-carboxylate reductase in root/nodule and leaf of soybean. Plant Physiology, 99(4): 1642-1649.

Tesfaye, S.G., Ismail, M.R., Ramlan, M.F., Marziah, M. and Kausar, H. 2014. Effect of soil drying on rate of stress development, leaf gas exchange and proline accumulation in Robusta coffee (Coffea scanephora Pierre ex Froehner) clones. Experimental agriculture, 50(3): 458-479.

Tounekti, T., Mahdhi, M., Al-Turki, T.A. and Khemira, H. 2018. Water relations and photo-protection mechanisms during drought stress in four coffee (Coffea arabica L.) cultivars from southwestern Saudi Arabia. South African journal of botany, 117: 17-25.

Venkataramanan, D. 1985. Physiological studies in coffee (PhD Thesis). University of Mysore, India, p. 157.

Verbruggen, N. and Hermans, C. 2008. Proline accumulation in plants: a review. Amino acids, 35 (4): 753-759.

Verbruggen, N., Villarroel, R. and Van Montagu, M. 1993. Osmoregulation of a pyrroline-5-carboxylate reductase gene in Arabidopsis thaliana. Plant Physiology, 103(3): 771-781.

Yoshiba, Y. 1995. Correlation between the induction of a gene for delta-pyrroline-5-carboxylate synthetase and the accumulation of proline in Arabidopsis thaliana under osmotic stress. Plant Journal, 7: 101-110. 